\title{
Direitos linguísticos de solicitantes de refúgio no Brasil: a presença do mediador linguístico na entrevista de solicitação de refúgio como garantia de direitos humanos
}

Ana Cristina Balestro ${ }^{a}$

Sabine Gorovitz ${ }^{b}$

\begin{abstract}
Resumo
A presente discussão, que se estabelece no âmbito dos estudos em Políticas Linguísticas, concentra-se na centralidade do papel do intérprete comunitário como garantia do cumprimento dos direitos linguísticos no contexto migratório contemporâneo brasileiro. $O$ foco recai especialmente na situação determinante da entrevista do solicitante de refúgio com o oficial de elegibilidade do Comitê Nacional para os Refugiados - CONARE, situação sociolinguística peculiar que embasa a deliberação sobre a concessão do status de refugiado no país. Ressalta-se a ausência de uma política explícita atual, especialmente em termos de direitos linguísticos, um vácuo institucional que se faz sentir considerando-se, ainda mais, os impactos dos deslocamentos forçados, em meio a uma crise humanitária global, que resulta no aumento significativo das mobilidades e, como consequência, de solicitações de refúgio no país e no
\end{abstract}

Recebido em: $21 / 09 / 2020$ Aceito em: 11/11/2020

a Universidade Federal Fluminense, Departamento de Letras Estrangeiras Modernas; Programa de PósGraduação em Estudos de Linguagem. Niterói, RJ, Brasil. E-mail: acbalestro@id.uff.br

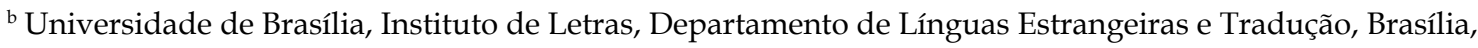
DF, Brasil. E-mail: sabinegz@gmail.com

\section{Como citar:}

Balestro, A. C.; Gorovitz, S. Direitos linguísticos de solicitantes de refúgio no Brasil: a presença do mediador linguístico na entrevista de solicitação de refúgio como garantia de direitos humanos. Gragoatá, Niterói, v.26, n.54, p. 355-379, 2021. <https://doi.org/10.22409/gragoata.v26i54.46258> 
${ }^{1}$ Em 2015, haitianos deixaram de ser considerados refugiados para receberem o visto humanitário no Brasil, causando uma queda no número de solicitações de refúgio. No entanto, já despontava aumento de $307 \%$ nas solicitações de refúgio de venezuelanos em 2016 em comparação a 2015.

\footnotetext{
${ }^{2}$ Para análise dos números de refúgio no Brasil, consideramos aqui aqueles divulgados oficialmente pela Polícia Federal e em conjunto com o Comitê Nacional para os Refugiados - Conare. O Conare atua sob o Ministério da Justiça e Segurança Pública. Estes são os órgãos responsáveis por protocolar e definir as solicitações de refúgio no Brasil.
}

mundo. A investigação consistiu-se em uma pesquisa qualitativa descritiva das ações desempenhadas por instituições do Estado e da Sociedade Civil, alicerçada na legislação e em sites oficiais sobre refúgio no Brasil. Para dar conta dos desafios da análise, lança-se mão de um referencial teórico de Política Linguística e de Glotopolitica (CALVET, 2007; LAGARES, 2018), concentrando em estudos de direitos linguísticos (HAMEL, 1995, 2003; OLIVEIRA; SILVA, 2017; SCHNEIDER-MIZONY, 2018; VARENNES, 2001, 2015). Com base nesse corpus, verifica-se a necessidade premente da implementação de ações, especialmente de mediação linguística em contextos institucionais, iniciativas que deveriam ser pautadas pelo Estado brasileiro, cuja inércia tem sido compensada pela academia e pela Sociedade Civil.

Palavras-chave: Política linguística. Refúgio. Direitos linguísticos. Intérprete Comunitário.

\section{Introdução}

O Brasil exibe, como muitos países no mundo, estatísticas alarmantes ${ }^{1}$ : em 2019, a Polícia Federal ${ }^{2}$ registrou um aumento de mais de $330 \%$ do número de solicitações de refúgio desde 2016. O relatório "Refúgio em Números", elaborado pelo Ministério da Justiça e Segurança Pública (MJSP) e pelo Comissariado das Nações Unidas para Refugiados - Acnur, na edição publicada em 2019, aponta que o Brasil recebeu 80.000 solicitações de refúgio, só em 2018. Ainda que esse número represente uma porcentagem pouco significativa considerando outros países que vêm acolhendo refugiados na África, no Oriente Médio e na Europa, ele tem crescido exponencialmente, o que coloca a questão das migrações nas pautas do Estado brasileiro.

Para solicitar refúgio, os proponentes devem comprovar que sofrem violação grave e generalizada de direitos humanos ou apresentar justificativas fundamentadas em temores de perseguição por motivos de raça, religião, gênero ou opinião política em seus países. Ainda que considerada a maior crise de deslocamento forçado desde a Segunda Guerra Mundial e com grande notoriedade em âmbito global, no Brasil a questão do 
${ }^{3}$ Em 2018, venezuelanos representavam $52 \%$ das solicitações de refúgio em trâmite no Brasil (MJSP, 2019). deslocamento forçado tem sido destaque apenas recentemente, com os impactos causados pelo aumento de venezuelanos solicitando refúgio, concentrados, principalmente, no estado de Roraima ${ }^{3}$.

De acordo com estudo realizado pelo Instituto de Pesquisa Econômica Aplicada (IPEA, 2015) e com pesquisas da área de linguística aplicada (BARBOSA; RUANO, 2016; GROSSO, 2010; PEREIRA, 2017), as fronteiras linguísticas configuram o principal desafio a ser enfrentado. A ausência de políticas públicas, especialmente para garantir a presença de um mediador linguístico, ameaça os direitos linguísticos e humanos dessas populações (OLIVEIRA; SILVA, 2017; VARENNES, 2001, 2015). De fato, saber o idioma do país de acolhimento é condição de acesso a direitos, como documentação e serviços públicos.

Nesse contexto, urge o reconhecimento da obrigação de o Estado brasileiro prover um apoio linguístico para garantir o devido diálogo entre pessoas imigrantes, refugiados e minorias linguísticas que não falam (ainda) o português e que necessitam desse apoio na sua relação com as instituições públicas, em diversos contextos de acesso a direitos: saúde, justiça, educação, fronteiras, etc. Trata-se de incluir na pauta os direitos de essas pessoas de estar linguisticamente presentes nessas situações em que a proficiência linguística seria condição para explicar os antecedentes que os forçaram a sair de seus países: o direito a uma mediação linguística por meio de um profissional denominado no Brasil de "intérprete comunitário ou intérprete colaborativo", de modo a garantir sua ampla defesa e o acesso aos direitos humanos aos quais faz jus.

De forma panorâmica, a interpretação comunitária se faz necessária por garantir a participação linguística de todos os sujeitos pertencentes a minorias linguísticas sub ou não representadas no país, sejam eles imigrantes, indígenas, surdos, mudos ou sejam cegos em situações de interação, especialmente com as instituições públicas provedoras e que devem ser garantidoras efetivas e eficazes de direitos. Somente a atuação de um mediador linguístico profissional qualificado pode garantir a participação e a presença linguística dessas pessoas. Deixar este trabalho a cargo de falantes bilíngues sem treinamento, tal como ocorre hoje em muitos espaços, é um desrespeito aos direitos fundamentais previstos pela Constituição brasileira e em acordos internacionais de direitos 
${ }^{4}$ Os direitos

linguísticos estão especialmente

consignados na

Declaração Universal

dos Direitos

Linguísticos, retificada

em Barcelona em

1996 http://www.

dhnet.org.br/direitos/

deconu/a_pdf/

dec_universal_

direitos_linguisticos.

pdf. Acesso em: 17 out.

2020. humanos como, por exemplo, o Pacto de San José da Costa Rica, ratificado pelo Brasil na Convenção de Direitos Humanos das Américas. ${ }^{4}$

Nesse contexto, a implementação de políticas linguísticas, que entraram na pauta do Estado brasileiro somente de forma restritiva e repressora (a exemplo das políticas varguistas dos anos 1930 que proibiam a prática de línguas ditas "minoritária"), é de extrema urgência. Ainda que o país apresente um cenário consolidado de contatos entre populações e línguas, as discussões em âmbito institucional em torno das questões linguísticas são incipientes, para não dizer inexistentes. As deficiências institucionais com relação às comunidades migrantes e outras minorias e seus direitos linguísticos têm sido compensadas por iniciativas solidárias e discussões restritas à academia e à Sociedade Civil por meio de organizações não governamentais e religiosas, ainda que muitas ações sejam implementadas em diálogo com instituições públicas.

Com exceção de algumas pautas, conquistadas por certas minorias, como a comunidade dos surdos, que alcançou seu direito a Libras, hoje reconhecida como meio legal de comunicação e de expressão, e algumas comunidades indígenas e outras de imigração mais consolidada, com a cooficialização de algumas de suas línguas, a ausência de políticas e mecanismos de inclusão linguística efetivos revelam como o Estado brasileiro não está conseguindo respaldar adequadamente suas instituições públicas na garantia dos direitos das populações linguisticamente minoritárias. De fato, a integração linguística e social dos imigrantes, refugiados, apátridas, estabelece-se por meio de leis e decisões políticas, mas também se constrói com ações de longo prazo em sinergia entre diversos agentes, num processo que implica toda a sociedade, em especial os próprios imigrantes.

Partindo de tais premissas, propõe-se uma reflexão sobre as fronteiras linguísticas que devem ser ultrapassadas pelo solicitante de refúgio no Brasil na situação sociolinguística específica da entrevista junto ao Conare. Nossa análise se pauta em uma pesquisa documental, sob a perspectiva teórica dos estudos em Política Linguística, com particular enfoque na atuação do intérprete comunitário, profissional que, embora 
${ }^{5}$ Dados disponíveis na página virtual da agência das Nações Unidas para Refugiados. Disponível em: https://www. unhcr.org/figures-at-aglance.html Acesso em: 04 set. 2019.

\section{${ }^{6}$ Nações Unidas} Brasil. Disponível em https://nacoesunidas. org/populacao-demigrantes-no-brasilaumentou-20-noperiodo-2010-2015revela-agencia-daonu/. Acesso em: 03 mar. 2019. não reconhecido no Brasil, vem ganhando destaque no cenário migratório atual.

\section{Direitos linguísticos de refugiados}

Atualmente, o movimento migratório vem atingindo números que causam inquietação: globalmente, estima-se que 70,8 milhões de pessoas estão em situação de deslocamento forçado, das quais 41,3 milhões são pessoas internamente deslocadas, 25,9 milhões são refugiados e 3,5 milhões estão em busca de asilo ${ }^{5}$. Proporcionalmente, o fenômeno ainda não se configura de maneira numericamente expressiva no Brasil: de acordo com dados da Organização Internacional para as Migrações (OIM), em 2015, a parcela de migrantes internacionais no Brasil ficava em torno de $0,3 \%$ da população ${ }^{6}$. $\mathrm{O}$ fenômeno migratório, no entanto, vem se tornando mais expressivo em pesquisas e na mídia, em razão dos impactos na sociedade, com imigrantes em situação vulnerável, em busca de integração local e de empregos. A situação de instabilidade e exclusão acarreta o aumento de desigualdades sociais e abre espaço à violação de direitos básicos, contexto no qual se destaca a necessidade de políticas públicas inclusivas:

[...] a inclusão da população migrante e refugiada nas políticas públicas pensadas em uma perspectiva integral e transversal favorece a integração e a prevenção de violações de direitos. Desigualdade não se combate com igualdade; se previne com equidade. (LUSSI, 2015, p. 136)

Diante desse cenário, a discussão acerca do tema requer que se trace um panorama dos direitos e das políticas linguísticas, com particular enfoque no caso de solicitação de refúgio.

O desenvolvimento de estudos sociolinguísticos relacionando língua e poder, com atenção às funções que as práticas linguísticas desempenham na vida social, traz à tona a premissa dos direitos linguísticos das minorias linguísticas. Ao longo da década de 1980, surgem abordagens distintas, com interesse pelas políticas linguísticas e pelos fatores sociais e históricos que as impactam. Cresce assim a consciência por parte de linguistas das reivindicações sociais de minorias étnicas e da força das relações de poder e hierarquias sociais na defesa de seus idiomas. O planejamento "pós-moderno" 
passa a ter uma visão mais ecológica do cenário linguístico, que valoriza e protege a manutenção da diversidade, em sintonia com os direitos humanos (LAGARES, 2018).

Procura-se expor e refletir, com base nos estudos de políticas linguísticas, as línguas enquanto um direito (HAMEL, 1995; VARENNES, 2015; OLIVEIRA; SILVA, 2017; SCHNEIDER-MIZONY, 2018), ressaltando a vulnerabilidade de não se conhecer a língua oficial do país, especialmente no contexto de imigração de refúgio. De acordo com a Declaração Universal dos Direitos Linguísticos de 1996, os direitos devem ser percebidos pela ótica coletiva e individual. Aborda-se, por um lado, a relação entre as práticas em meio à diversidade linguística e cultural, que simultaneamente consolida e ameaça a coesão social; por outro, a questão estruturante da gestão das línguas, seja por um mesmo indivíduo, inserido dentro de uma comunidade, seja pela implementação de políticas linguísticas, com seus múltiplos desdobramentos sociais. A Declaração da Unesco, resultado de um movimento de legitimação de direitos de minorias étnicas, culturais e linguísticas, é assinada em Barcelona e atua como uma orientação no trato e entendimento dos direitos linguísticos, como individuais, coletivos e fundamentais, porém não exerce o poder coercitivo de uma legislação. Hamel (1995) indica que a resistência à concessão de direitos linguísticos a minorias parte da crença de que a diversidade linguística coloca em risco a unidade e soberania da nação e a coesão social, ameaçando a segurança nacional. Em reação, a Declaração estabelece que o respeito e a não repressão linguística são direitos do migrante a manifestar sua cultura, religião ou estilo de vida.

A Declaração Universal dos Direitos Linguísticos desponta considerando o estabelecido na Declaração Universal dos Direitos Humanos (DUDH) de 1948 que estabelece, em seu segundo Artigo, que todos têm direitos e liberdade, independentemente de qual seja sua raça, cor, sexo, língua, religião, opinião política, origem nacional ou social, ou outra condição; considera, também, demais deliberações jurídicas que respeitam os direitos humanos e que reconhecem o impacto das colonizações nas línguas dos grupos minorizados. Sob essa perspectiva, depreende-se que os direitos linguísticos "fazem parte dos direitos humanos fundamentais, tanto individuais como coletivos, e se sustentam nos princípios universais da 
dignidade dos humanos e da igualdade formal de todas as línguas" (HAMEL, 2003, p. 50-51).

No caso de refúgio, o direito linguístico não se restringe a uma comunidade e a uma língua minorizada, nem se aplica a um território, pelo contrário, ele transpõe a limitação geográfica. Ainda que se possa reconhecer que, do ponto de vista administrativo, uma unidade linguística facilitaria tarefas, ressalta-se a necessidade da reflexão do direito linguístico como humano e individual (SCHNEIDER-MIZONY, 2018). A língua como direito prevê a não discriminação linguística e a promoção da inclusão na sociedade de acolhimento, de maneira a abranger integração no meio trabalhista, no sistema de saúde, na educação, no conhecimento jurídico, entre outros. Salientase aqui que não saber falar a língua oficial de um país não pode ser impedimento para acesso aos direitos civis.

Os direitos linguísticos estão intimamente vinculados a direitos fundamentais e a direitos coletivos, tais como o direito ao território e à educação específica, de forma que:

[...] o discurso pelos direitos linguísticos, ao invés de representar uma resistência à mudança e à modernização, representaria uma entre várias estratégias de manipulação e reapropriação dos direitos modernos que caracterizam as práticas políticas contemporâneas dos grupos minoritários. (SILVA, 2017, p. 671)

Nesse contexto, para dar conta da situação de refúgio, caracterizada por uma superdiversidade linguística, uma sociolinguística precisa somar-se às do direito, buscando descrever "em detalhe os processos sociais e culturais em torno das línguas para as quais estão em jogo os direitos linguísticos. (HAMEL, 2003, p. 66). Assim, faz-se imprescindível a análise conjunta dos direitos linguísticos e das práticas jurídicas e administrativas vigentes.

\section{Legislação vigente}

As leis que regulam a vida dos migrantes no Brasil, bem com a legislação especificamente voltada à migração de refúgio, regulamentando obrigações e deveres, tanto por parte do Estado como do migrante, passaram por alterações ao longo dos últimos anos. Eventos de ordem geopolítica também tiveram influência, como o fim da Segunda Guerra Mundial 
${ }^{7}$ Ministério da Justiça e Segurança Pública. Disponível em: <https://www.justica. gov.br/seus-direitos/ refugio/anexos/ap-aso.pdf $>$. Acesso em: 22 out. 2019. e o intenso fluxo de refugiados. Por isso, cada Estado adere a leis internacionais e desenvolve as suas próprias políticas migratórias de acordo com sua realidade.

Políticas migratórias são aquelas que interferem, de alguma maneira, nos movimentos migratórios: podem restringir ou estimular o fluxo migratório, regular a concessão de vistos, diminuir burocracias, facilitar empregabilidade, etc. São direcionamentos do governo que têm grande impacto na integração social dos solicitantes de refúgio.

A figura a seguir, disponível no site do Ministério da Justiça e Segurança Pública ${ }^{7}$, apresenta o fluxo administrativo de uma solicitação de refúgio, que deve iniciar-se na Polícia Federal e ser deliberada pelo Conare.

Figura 1 - Fluxograma da Solicitação de Refúgio

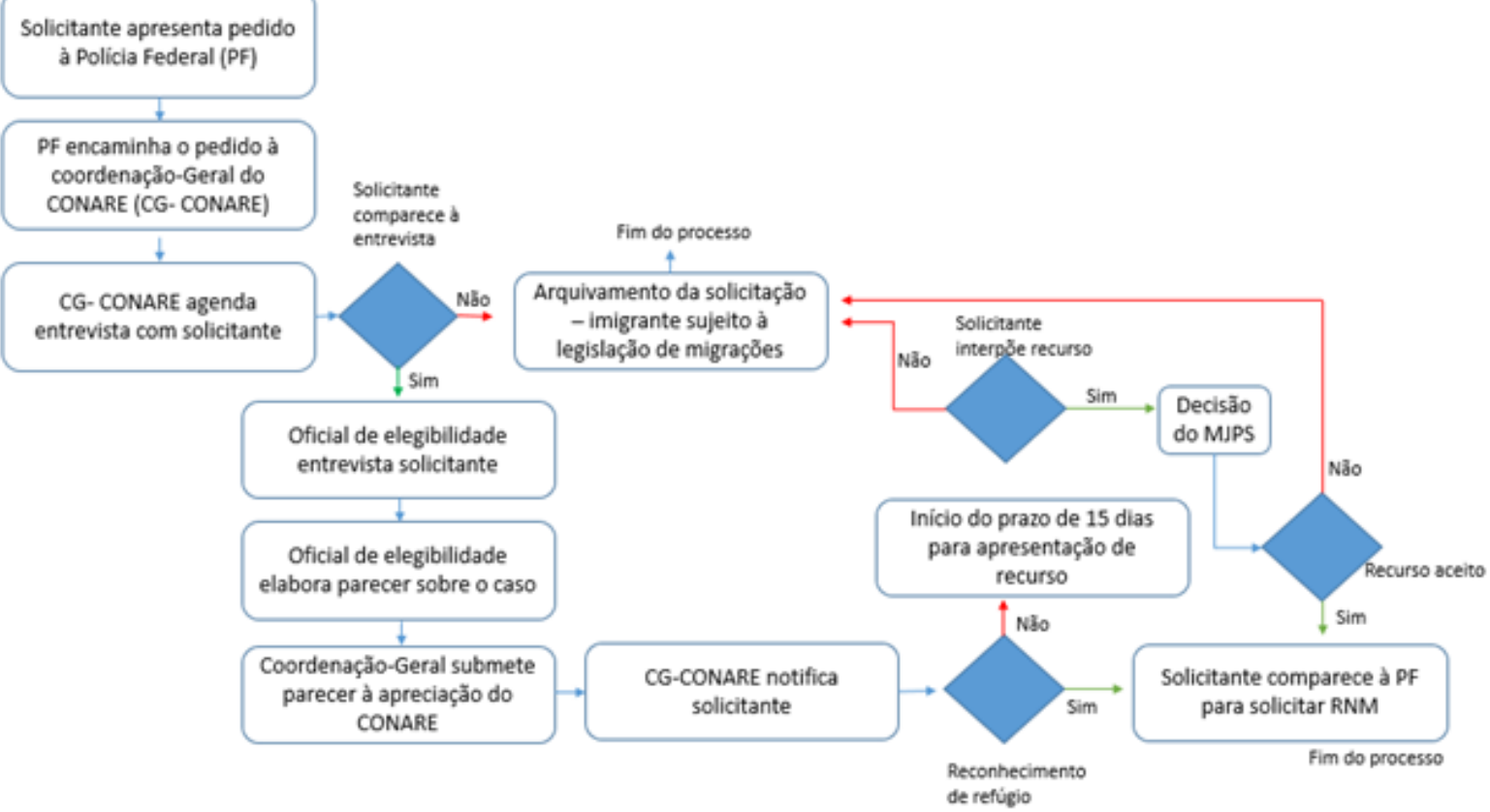

Fonte: MJSP.

O fluxograma exposto apresenta o caminho percorrido administrativamente pelo processo de solicitação de refúgio, destacando a atuação dos entes estatais envolvidos, notadamente a Polícia Federal, o CONARE e o Ministério da Justiça e Segurança Pública. 
Criado a partir da homologação da Lei 9.474 de 1997, o Conare é um órgão de deliberação coletiva, vinculado ao Ministério da Justiça e Segurança Pública. De acordo com o seu regimento interno, suas atribuições são:

I - analisar o pedido e decidir sobre o reconhecimento da condição de refugiado;

II - deliberar quanto à cessação, ex ofício ou mediante requerimento das autoridades competentes, da condição de refugiado;

III - declarar a perda da condição de refugiado;

IV - orientar e coordenar as ações necessárias à eficácia da proteção, assistência, integração local e apoio jurídico aos refugiados, com a participação dos Ministérios e instituições que compõem o CONARE;

$\mathrm{V}$ - aprovar instruções normativas que possibilitem a execução da Lei no 9.474/97. (BRASIL, 1998. Art. $2^{\circ}$ ).

Na composição do colegiado, é necessário constar: (i) representantes dos ministérios da Justiça e Segurança Pública, das Relações Exteriores, do Trabalho, da Saúde, da Educação e do Desporto; (ii) um representante do Departamento da Polícia Federal; (iii) um representante de uma organização não governamental que se dedique ao trabalho com assistência e proteção de refugiados, e (iv) um representante do Acnur, com direito à voz, mas sem direito a voto nas deliberações. Por sua composição, o Conare é um órgão vinculado ao governo, porém é um exemplo de trabalho orquestrado com a Sociedade Civil.

A esfera normativa é a estrutura de política legislativa migratória que não só determina o fluxo do processo de solicitação de refúgio, mas também possibilita e regula a atuação das instituições envolvidas.

A legislação que embasa o trâmite de solicitação de refúgio passou a ser desenhada a partir da Convenção das Nações Unidas de 1951, ratificada pelo Brasil em 1960. A Convenção definiu os motivos para que um migrante seja oficialmente considerado um refugiado. $\mathrm{O}$ documento, no entanto, abrangia apenas os eventos ocorridos antes de $1^{\circ}$ de janeiro de 1951, englobando a migração na Europa pós-Segunda Guerra Mundial. Porém, com os demais fluxos migratórios, fez- 
${ }^{8}$ Ministério das Relações Exteriores. Disponível em: http:// www.portalconsular. itamaraty.gov.br/ refugio-no-brasil. Acesso em: 09 abr. 2019.

${ }^{9}$ Ministério das Relações Exteriores. Disponível em: http:// www.portalconsular. itamaraty.gov.br/ refugio-no-brasil. Acesso em: 10 jul. 2019.

${ }^{10}$ Dados extraídos de Acnur. Disponível em: <http://www. acnur.org/portugues/ noticias/noticia/ refugiado-oumigrante-o-acnurincentiva-a-usaro-termo-correto/>. Acesso em: 12 mar. 2018. se necessário um novo Protocolo, que não restringia datas ou limite geográfico específicos na definição de refúgio.

O Portal Consular ${ }^{8}$ do Ministério das Relações Exteriores ratifica a lei brasileira e reconhece como refugiado:

[...] todo indivíduo que sai do seu país de origem devido a fundados temores de perseguição por motivos de raça, religião, nacionalidade, grupo social ou opiniões políticas imputadas, ou devido a uma situação de grave e generalizada violação de direitos humanos no seu país de origem.

Considera-se que uma pessoa é perseguida quando seus direitos humanos tenham sido gravemente violados ou estão em risco de sê-lo. Isso pode acontecer, por exemplo, quando a vida, liberdade ou integridade física da pessoa corria sério risco no seu país. (MINISTÉRIO DAS RELAÇÕES EXTERIOES, on-line. $)^{9}$

O status de refugiado assegura proteção e é considerado um direito internacional. Visto que o Brasil é signatário da Convenção de 1951, é garantida a não expulsão e não devolução dos solicitantes quando sua vida e liberdade estejam em perigo ${ }^{10}$. Uma vez solicitado o pedido de proteção a uma autoridade migratória, o migrante não poderá ser deportado. Esse princípio é mais conhecido pela expressão que o originou, non-refoulement (não-devolução), em francês.

Assim que a solicitação é registrada junto à Polícia Federal, é emitido um protocolo (Decreto $n^{\circ}$ 9.277/2018), e o solicitante recebe gratuitamente o Documento Provisório de Registro Nacional Migratório (RNM). O Conare avalia as cláusulas de inclusão e de exclusão: as primeiras se referem aos requisitos para que seja concedido o status de refugiado, isto é, que seja admitido como verdadeiro o fundado temor previsto na Convenção; as cláusulas de exclusão são as que listam os requisitos que impedem a concessão do status, por exemplo, ter praticado crime de guerra, crime contra a paz, crime contra a humanidade, crime hediondo, atos de terrorismo ou tráfico de drogas (Estatuto do Refugiado, Lei 9.474/1997). Após os trâmites previstos por lei, caso seja reconhecida a existência de fundado temor em retornar ao seu país por ameaças pelos motivos descritos na Convenção de 51 e assim reconhecida 
${ }^{11}$ The magnitude of the community interpreter's responsibility can only be understood when realising that their work is crucial for the lives of innumerable people who would be unable to communicate without their services. According to Garber, 'the circumstances in which community interpreters practise carry even more risk and more responsibility than conference interpreting' (2000, p. 19). (HALE, 2007, p. 26).

${ }^{12}$ The term Community Interpreting has been used with slightly different meanings around the world. In some countries the term refers to ad hoc, unpaid interpreting conducted by volunteers (Dueñas González et al., 1991); in some it refers to the health and welfare sectors only (Pöchhacker, 1999); in others it is used more broadly to include all types of interpreting other than Conference Interpreting (Roberts, 1997; Ozolins, 1998); and in countries such as Denmark, they are still struggling to find a term that suits their language and situation.4 (HALE, 2007, p. 28) a condição de refugiado, acontece a aprovação do pedido de refúgio, concedida pelo Conare.

\section{O intérprete comunitário}

De acordo com Hale (2007, p. 25), a grande diferença entre os demais serviços de interpretação e o chamado serviço de interpretação comunitária é que este lida com as esferas mais íntimas de uma pessoa. O contexto envolvido é aquele da vida privada, com o qual o intérprete se compromete a manter a confidencialidade e que envolve a responsabilidade de lidar com um momento decisivo na vida de outrem:

\begin{abstract}
A magnitude da responsabilidade do intérprete comunitário só pode ser entendida quando se percebe que seu trabalho é crucial para a vida de inúmeras pessoas que seriam incapazes de se comunicar sem seus serviços. Segundo Garber, "as circunstâncias em que trabalham os intérpretes comunitários carregam ainda mais riscos e mais responsabilidades do que a interpretação da conferência". (2000, p. 19) (HALE, 2007, p. 26, tradução nossa) ${ }^{11}$.
\end{abstract}

A autora destaca a necessidade de um intérprete competente e ético, pois seu papel será o de elo entre os participantes. Há debates sobre as diferenças nos serviços de interpretação e mesmo sobre a melhor terminologia para defini-lo (HALE, 2007; OZOLINS, 2010), sendo que o termo mais recorrente é o que se traduz por "intérprete comunitário":

O termo Interpretação Comunitária tem sido usado com significados ligeiramente diferentes em todo o mundo. Em alguns países, o termo refere-se à interpretação ad hoc e não remunerada, conduzida por voluntários (DUEÑAS GONZÁLEZ et al., 1991); em alguns, refere-se apenas aos setores de saúde e bem-estar (PÖCHHACKER, 1999); em outros, é usado de forma mais ampla para incluir todos os tipos de interpretação que não sejam Interpretação de Conferências (ROBERTS, 1997; OZOLINS, 1998); e em países como a Dinamarca, eles ainda estão lutando para encontrar um termo que se adapte ao seu idioma e situação. (HALE, 2007 , p. 28, tradução nossa) ${ }^{\mathbf{1 2}}$

Assim, para o nosso contexto, adotamos o termo "intérprete comunitário", conforme proposto por Hale (2007), considerando as situações sociolinguísticas de interpretação que se configuram no contexto migratório, e que traz o enfoque 
da interpretação como um serviço prestado. De acordo com a autora, duas principais especializações se destacam na interpretação comunitária: a médica e a legal. Outras categorias incluem migração de maneira geral e educação, por exemplo. Para nossa pesquisa, o intérprete comunitário atua no contexto da entrevista entre o solicitante de refúgio e o oficial de elegibilidade do Conare. Essa modalidade de interpretação, por muito tempo desconsiderada pelos profissionais da interpretação de conferência, tem ganhado destaque com a intensificação dos deslocamentos forçados em contexto global, dada a crescente demanda por serviços de tradução em circunstâncias multilíngues.

\section{Entrevista com o Conare}

Focaliza-se aqui a entrevista com um representante do Conare, momento em que o solicitante de refúgio conta sua história e advoga a seu favor. Caso a decisão seja deferida, o solicitante passa a ter direito ao Registro Nacional de Estrangeiros (RNE), que autoriza a residência no Brasil. Se a decisão for negativa, o solicitante é notificado pela Polícia Federal, podendo, ainda, protocolar recurso que será remetido ao Ministério da Justiça para análise. Caso a solicitação seja novamente negada, o solicitante passa a ficar sujeito à legislação em vigor que se refere a estrangeiros, perdendo direitos garantidos a refugiados e com necessidade de regularizar seu visto no Brasil.

Uma vez descritas as instruções oficiais sobre o procedimento da entrevista, realizada de forma presencial ou por vídeo, como acontece no caso de residentes de cidades onde não há representação física do Conare, destacam-se aqui as ações glotopolíticas para que os solicitantes de refúgio tenham, de fato, seus direitos linguísticos respeitados durante a entrevista. Nesse sentido, investigou-se a ocorrência de serviços de interpretação, sejam oficiais sejam por meio de voluntariado. A análise norteou-se pela pesquisa de Uldis Ozolins (2010), Fatores que determinam o fornecimento de serviços de interpretação no serviço público: perspectivas comparativas sobre motivações governamentais e a implementação de serviços linguísticos, a fim de avaliar a prestação de serviços públicos de interpretação no Brasil, em comparação com os serviços oferecidos por diversos 
${ }^{13}$ Ressalta-se que, ainda que na maioria dos casos a entrevista ocorra somente dois a três anos após a solicitação de refúgio junto à Polícia Federal, a dificuldade de interação ainda se faz presente.

\footnotetext{
${ }^{14} \mathrm{~A}$ iniciativa é fruto de uma parceria entre o Ministério da Justiça do Governo Federal e a Universidade de Brasília, pela qual é fornecido serviço de intérpretes voluntários durante as entrevistas com o Conare.
}

${ }^{15}$ Help Acnur Brasil. Disponível em: $<$ https://help.unhcr. org/brazil/asylumclaim/>. Acesso em: 7 out. 2019 . países como resposta às necessidades crescentes da diversidade linguística. $\mathrm{O}$ autor fundamenta o serviço de interpretação comunitária e analisa as leis e práticas de um total de 15 países, com diferentes fluxos migratórios, juntamente com o tratamento direcionado a minorias linguísticas.

Com base nos estudos de Ozolins (2010), apontam-se os possíveis benefícios de um serviço público de mediação linguística (serviço comumente referido como intérprete comunitário) como uma ação necessária na recepção e inclusão de imigrantes na sociedade de acolhimento.

Durante uma entrevista, última etapa do processo de solicitação de refúgio, que dura em média uma hora, o foco repousa nos motivos que definem o deferimento do pedido do solicitante e na veracidade de sua história. O roteiro de uma entrevista de solicitação de refúgio (GARCIA, 2019a, p. 120-125) divide-se em três partes: a primeira foca informações sobre o perfil individual do solicitante, documentação, datas de saída e chegada, membros da família, religião, etnia, educação, entre outros. A segunda parte volta-se aos motivos que ensejaram a saída do seu país, com perguntas sobre o tipo de perseguição sofrido, se foi preso, a relação com a polícia no país de origem etc. A terceira parte concentra-se nos motivos que impossibilitam o retorno do solicitante ao seu país ${ }^{13}$.

Descrevem-se, a seguir, o papel do intérprete durante a entrevista, bem como o projeto Mobilang, que ocorre desde 2017 e visa a prestar um serviço voluntário de mediação linguística de modo a sanar ou a amenizar as consequências dessa lacuna ${ }^{14}$.

\section{A presença do intérprete durante a entrevista}

Como indicado anteriormente, a entrevista é o momento em que o solicitante vai narrar, desta vez pessoalmente e não por meio de um formulário como o que preencheu no Sisconare no momento de submeter a solicitação, sua história para um representante do Conare, sendo um momento sensível que pode reavivar traumas e que requer cooperação verbal das partes. De acordo com o disposto nas orientações da página internacional do Acnur na plataforma Help Acnur ${ }^{15}$, cabe ao solicitante a responsabilidade de ser acompanhado por um 
${ }^{16}$ Fernanda Garcia (2019a) conduziu uma pesquisa empírica em seu mestrado em estudos de tradução (Postrad - UnB).
${ }^{17}$ Help Acnur Brasil. Disponível em: <https://help.unhcr. org/brazil/asylumclaim/como-possosolicitar-refugio-estouem-pacaraima/> Acesso em: 4 out. 2019.
${ }^{18}$ Caso o solicitante de refúgio não compareça acompanhado de um intérprete e não consiga comunicar-se, a entrevista é suspensa e uma nova data será remarcada. intérprete, uma vez que a previsão é que a entrevista ocorra em português.

Isso é muito importante porque se você não levar um intérprete e não houver alguém para fazer a tradução simultânea oficialmente, sua entrevista será cancelada. Atualmente, o CONARE tem funcionários que falam apenas português, inglês, espanhol e francês que não estão sempre disponíveis no momento da entrevista. Portanto, se você não fala nenhuma destas línguas, assegure-se de levar alguém que você confia para ser seu tradutor e se você não conhecer alguém que possa ajuda-lo, contate o ACNUR ou um dos seus parceiros. (DPU, ACNUR, 2013)

Como apontado anteriormente, alguns solicitantes apresentam certa fluência em português pelo fato de a entrevista ocorrer em média quatro anos após a apresentação da solicitação de refúgio à Polícia Federal (GARCIA, 2019a) ${ }^{16}$. Quando há a necessidade de interpretação, o serviço é voluntário, nos casos em que é oferecido.

Atualmente, no Brasil, todos os serviços de interpretação comunitária são feitos voluntariamente, isto é, ainda não existem intérpretes comunitários profissionais ou funcionários públicos. Embora a Cartilha para Solicitantes de Refúgio no Brasil (ACNUR, 2014) afirme que o solicitante tem direito a um intérprete, nas entrevistas de solicitação de refúgio, o próprio solicitante acaba sendo o responsável por levar consigo alguém para mediar sua interação com o oficial de elegibilidade. (GARCIA, 2019b, p. 77)

Não há, no Brasil, intérpretes comunitários públicos. De acordo com as informações sobre como solicitar refúgio disponibilizadas no Help Acnur Brasil ${ }^{17}$, o Conare dispõe de funcionários que podem realizar a entrevista em inglês, espanhol e francês, mas não garante a sua disponibilidade no momento da entrevista, razão pela qual a plataforma da Acnur reafirma a necessidade de o solicitante certificar-se de ter alguém de sua confiança que possa atuar como intérprete ${ }^{18 .}$

Sendo assim, os intérpretes que acompanham as entrevistas de solicitação de refúgio são sempre voluntários e, na maioria das vezes, eles costumam ser outros imigrantes que já conseguiram o status de refugiado, ou algum membro da comunidade do país de origem do solicitante no Brasil. Como é possível imaginar, há diversas variáveis nessa situação 
${ }^{19}$ Os padrões do Conare referidos podem ser interpretados como os de acordo com o Manual desenvolvido pelo Acnur e DPU, porém não há

referência específica no Termo ou na página da internet. que carecem de investigação e análise, como, por exemplo, questões sociais, conflitos de interesse dos intérpretes, entre outros. (GARCIA, 2019a, 25)

Esses fatores afetam a entrevista e prejudicam o solicitante. A autora destaca que alguns dos motivos que justificam o fundado temor para que o solicitante não retorne ao seu país de origem é geralmente um tabu entre membros da comunidade, o que constrange fortemente o relato.

[...] há casos de pedido de refúgio pautados em perseguição por identidade de gênero ou orientação sexual, normalmente de países em que a relação homo afetiva é considerada crime [...]. O solicitante pode não se sentir confortável em compartilhar sua história e expor livremente os reais motivos para o refúgio, mesmo já estando no Brasil. (GARCIA, 2019a, p. 25)

O intérprete que comparecer deve assinar o Termo de Responsabilidade do Intérprete, disponível na página do MJSP, em português. Por meio desse documento, compromete-se com o sigilo das informações traduzidas, com a imparcialidade e fidelidade ao que está sendo relatado, devendo cumprir os "padrões do Conare em relação às questões culturais, de gênero e idade" (MJSP, Termo de Responsabilidade, item e, 2019b) ${ }^{19}$.

A necessidade de um serviço de interpretação comunitária qualificada nessa etapa do processo de solicitação de refúgio vem timidamente ganhando destaque, ainda que em descompasso com a crescente demanda que se apresenta. Nessa seara, postula-se o imperativo de profissionalização adequada desses intérpretes, de modo a responder às peculiaridades da situação:

[...] a) há maior variedade de línguas, em especial de línguas minoritárias, em contraste com as línguas majoritárias presentes nos contextos de diplomacia internacional; b) a presença do intérprete é muito mais notada, por se tratar de interações dialógicas e não unilaterais, o que consequentemente implica o intérprete traduzir de ambas as línguas e para ambas as línguas [...]. (GARCIA, 2019b, p. 72)

O manual desenvolvido pelo Acnur em parceria com a Defensoria Pública da União (DPU) indica orientações para a preparação do intérprete à entrevista, notadamente a pesquisa 
sobre as fases do processo e a terminologia relacionada. Dentre as recomendações sobre a postura do intérprete, constam a confidencialidade e a neutralidade:

\begin{abstract}
Os intérpretes devem entender que tudo o que o entrevistador e o solicitante digam deve ser traduzido. Não é suficiente resumir ou embelezar o que é dito, fornecendo informações que faltam. O intérprete não deve tentar melhorar as palavras ou frases do solicitante para torná-lo mais consistente, confiável e educado. O intérprete deve ser treinado para tomar notas durante a entrevista para garantir a precisão do que é traduzido e registrar todos os dados de forma clara. Qualquer nome de pessoa ou lugar deve ser escrito para que fique claro. O intérprete também deve entender que o entrevistador ou o solicitante podem fazer perguntas de esclarecimento, quando necessário. (DPU, ACNUR, 2013, p.13)
\end{abstract}

Garcia (2019a, 2019b) e Hale (2007) ressaltam que não há treinamento específico para o intérprete comunitário. Vale destacar que todo solicitante, seja qual for sua(s) língua(s) primeira(s), tem direito a uma entrevista na qual seja compreendido, sem que fique comprometida a narrativa de sua história. Esse direito, para ser assegurado, implicaria um custo financeiro para disponibilizar uma oferta de serviços desta natureza, especialmente ante a diversidade linguística acarretada pela entrada de imigrantes no país, de origem cada vez mais variada. Nesse sentido, Ozolins (2010) depreende de sua pesquisa que alguns fatores podem incentivar ou desmotivar o investimento em serviços públicos de interpretação, quais sejam:

- Posicionamentos políticos e sociais em relação à imigração e autoimagem de um país monolíngue e monocultural;

- Federalismo ou unitarismo nos governos e na relação com outras autoridades (países federalistas frequentemente apresentam variação na oferta de serviços de interpretação);

- Modelos de políticas públicas diferentes entre entes do governo e da Sociedade Civil quanto ao entendimento do que deve ser responsabilidade do Estado e o que pode ser provido pela Sociedade Civil; 
- A ênfase e a regulação destinadas à interpretação judicial em relação a outras modalidades de serviços de interpretação;

- Conduta em relação à terminologia própria no serviço público de interpretação, no sentido da promoção de debate em torno do serviço.

Com base nesses itens, percebe-se o Brasil como um país federalista frequentemente retratado como monolíngue, apresentando políticas públicas que hoje necessitam do trabalho conjunto de instituições públicas, acadêmicas e da Sociedade Civil. As discussões sobre a necessidade da intervenção de um mediador linguístico em espaços públicos no sentido de garantir os direitos ao solicitante de refúgio e às minorias linguísticas em geral são incipientes, para não dizer inexistentes.

Ressalta-se também que o Brasil, embora tenha historicamente recebido diversos fluxos de imigração, pouco fez pela implementação de políticas adequadas de acolhimento, ausentando-se da pauta de políticas e direitos linguísticos, com exceção da época do regime militar, quando implementou políticas de repressão linguística. Foi só recentemente que uma jurisdição mais positiva em relação à migração foi aprovada, embora desconsidere as questões de direitos linguísticos. Essa lacuna motivou a criação do projeto de extensão "Migrações e fronteiras no DF: a integração linguística como garantia dos direitos humanos", do grupo Mobilang, tal como descrito a seguir.

\section{Iniciativas não governamentais: o projeto Mobilang}

${ }^{20}$ Todas as informações sobre o projeto e o grupo de pesquisa foram retiradas do site oficial do Projeto Mobilang. Disponível em: <http://mobilang unb.br>. Acesso em: 9 ago. 2019 .
O Grupo de Pesquisa Mobilidade e Contato de Línguas - Mobilang ${ }^{20}$, do Departamento de Línguas Estrangeiras e Tradução do Instituto de Letras da Universidade de Brasília (UnB), dedica-se aos estudos das mobilidades de população e dos decorrentes contatos de línguas. Atualmente contam com oito linhas de pesquisa voltadas a temáticas relacionadas com migração, contato de línguas, multilinguismo e tradução, direitos e políticas linguísticas. Em 2014, o grupo implementou um projeto de extensão chamado "Migrações e fronteiras 
${ }^{21}$ Sediado em Brasília e com atuação nacional, o Instituto Migrações e Direitos Humanos é uma associação sem fins lucrativos e vinculada à Congregação das Irmãs Scalabrianas, com mais de vinte anos de atuação dedicada ao atendimento jurídico e socioassistencial, à acolhida humanitária, à promoção da inserção social e laboral de migrantes, solicitantes de refúgio, refugiados e apátridas. no DF: a integração linguística como garantia dos direitos humanos", voltando a atenção para as dificuldades linguísticas enfrentadas pelos migrantes solicitantes de refúgio. Nesse projeto, o grupo estabeleceu vínculo com o Instituto Migrações e Direitos Humanos ${ }^{21}$, a fim de fortalecer sua atuação e nutrirse com informações provenientes das iniciativas da instituição que lida diariamente com migrantes.

Com base na compreensão da necessidade de serviços de interpretação comunitária, o grupo desenvolveu um Banco de Intérpretes voluntários para compensar a lacuna de prestação dessa mediação por parte do serviço público, tendo prestado expressivo apoio ao Conare.

O banco de intérpretes do MOBILANG atualmente conta com mais de 60 intérpretes ativos, mas a maioria trabalha com as três línguas majoritárias, inglês, espanhol e francês. Existe uma demanda grande principalmente para o francês, mas ainda há uma boa parcela de solicitantes que não fala nenhuma dessas três línguas. O árabe completa o grupo dos idiomas em maiores demandas. (GARCIA, 2019b, p. 69)

Assim, o Banco de Intérpretes do Mobilang tem como principal objetivo prover um apoio linguístico à população imigrante que chega ao Distrito Federal e, quando localizados em outros Estados, em entrevistas prestadas por meio de videoconferência. Os integrantes do banco interpretam durante as entrevistas de elegibilidade do Conare, órgão com o qual firmaram parceria:

Dessa forma, firmando parcerias com instituições que trabalham diretamente com a integração e assistência a refugiados e migrantes no país, o projeto propõe oferecer um suporte linguístico a eles, por meio da implementação de um banco de intérpretes voluntários. O CONARE (Comitê Nacional para Refugiados) é a primeira instituição com a qual o MOBILANG estabeleceu a parceria, fornecendo os serviços de mediação linguística nas entrevistas de solicitação de refúgio em situações em que o oficial de elegibilidade e o imigrante não falam a mesma língua. (GARCIA, 2019a, p. 12)

Segundo a plataforma virtual do projeto, o processo de prestação do serviço ocorre da seguinte forma: o Conare faz a solicitação da demanda via e-mail; o grupo Mobilang convoca os intérpretes conforme o idioma e a disponibilidade informada. 
${ }^{22}$ A plataforma virtual do grupo disponibiliza, na íntegra, os trabalhos elaborados pelo grupo, como por exemplo a dissertação "Migrações e impasses no acesso à saúde: traduzir-se é preciso" (MOLINA CABRERA, 2017), que disponibiliza, além de sua análise sobre tradução e acesso no campo da saúde, glossário bilíngue espanhol português com termos referentes à dor.
Tanto os intérpretes quanto os oficiais de elegibilidade recebem um formulário para que deem retorno de modo a avaliar a experiência com o serviço voluntário prestado. A proposta do projeto é estender a disponibilidade de serviços e constituir bancos terminológicos multilíngues ${ }^{22}$ que sejam viabilizados às instituições atuantes.

\section{Considerações finais}

Durante o processo migratório, é visível a ausência de políticas públicas de acolhimento, especialmente linguísticas, de forma que migrantes buscam apoio com redes de imigrantes e com a Sociedade Civil. Reflexões sobre as ações glotopolíticas nesse cenário contemporâneo de fluxo migratório de refúgio foi a temática da presente discussão, que teve como objetivo principal identificar, por meio de pesquisa documental, as questões glotopolíticas que comparecem nas entrevistas entre o refugiado e o representante do Conare, como condição do cumprimento dos direitos linguísticos dos solicitantes de refúgio. Nesse sentido, foi possível mapear o que vem sendo desenvolvido nesse contexto, focando o alcance e as limitações das eventuais ações glotopolíticas.

A aprovação da Lei de Migração Brasileira, de 2017, reforça a imagem de um Brasil comprometido com a Convenção de 1951. No entanto, ainda que a legislação atual seja considerada pela ONU como positiva em relação ao refúgio, concordamos com os autores Deusdará, Arantes e Rocha (2017), segundo os quais as políticas públicas carecem de ações para o acolhimento e a integração local dos solicitantes de refúgio. Esse fato ressalta a necessidade das iniciativas da Sociedade Civil, a exemplo da atuação de intérpretes comunitários e de grupos como o Mobilang.

No que diz respeito à decisiva entrevista entre o solicitante de refúgio com um representante do Conare, mais uma vez, pode-se observar a centralidade do intérprete voluntário. Entendemos a diversidade linguística como uma característica do movimento migratório atual, que não pode ser percebida como um impedimento, mas como uma oportunidade, dada sua relevância na construção e na expressão cultural de cada grupo. 
Por fim, reafirmam-se os preceitos de Lussi (2015) de que políticas públicas desempenham um papel determinante no fortalecimento ou enfraquecimento de desigualdades, as quais deveriam ser combatidas com ações que visam à equidade. A falta de informação e de acesso a direitos básicos bem como o não reconhecimento da diversidade linguística e cultural envolvida no processo migratório atuam como fatores que agravam a situação de vulnerabilidade das minorias linguísticas no país.

\section{REFERENCIAS}

BARBOSA, Lúcia Maria de A.; RUANO, Bruna P. Acolhimento, sentidos e práticas de ensino de português para migrantes e refugiados, na Universidade de Brasília e na Universidade Federal do Paraná. In: GEDIEL, José A. P.; GODOY, Gabriel G. de (org.). Refúgio e Hospitalidade. Curitiba: Kairós Edições, 2016. p. 321-336.

BRASIL. Constituição da República Federativa do Brasil de 1988. Brasília, DF: Presidência da República. Disponível em http:// www.planalto.gov.br/ccivil_03/constituicao/constituicao.htm. Acesso em: 05 dez. 2018.

BRASIL. Decreto $n^{0}$ 9.277, de 5 de fevereiro de 2018. Dispõe sobre a identificação do solicitante de refúgio e sobre o Documento Provisório de Registro Nacional Migratório. Brasília, DF: Diário Oficial da União. Disponível em http://www.planalto.gov.br/ ccivil_03/_ato2015-2018/2018/Decreto/D9277.htm. Acesso em: 23 set. 2019.

BRASIL. Lei n. 9.474, de 22 de julho de 1997. Define mecanismos para a implementação do Estatuto dos Refugiados de 1951, e determina outras providências. Brasília, DF: Diário Oficial da União. Disponível em http://www.planalto.gov.br/ccivil_03/ leis/19474.htm. Acesso em: 15 dez. 2018. 
BRASIL. Regimento interno do Comitê Nacional para os Refugiados - Conare. Brasília, DF: Diário Oficial da União, 06 de novembro de 1998, seção 1, p. 1-2. Disponível em https://www.refworld. org/pdfid/54e742a04.pdf. Acesso em: 03 fev. 2019.

MOLINA CABRERA, Marta Ingrith. Migrações e impasses no acesso à saúde: traduzir-se é preciso. Dissertação de Mestrado em Estudos da Tradução - Instituto de Letras, Universidade de Brasília, Brasília. 2017.

CALVET, Louis-Jean. As politicas linguísticas. São Paulo: Parábola, 2007; Florianópolis: IPOL, 2007.

DEFENSORIA PÚBLICA DA UNIÃO (DPU); ALTO COMISSARIADO DAS NAÇÕES UNIDAS PARA OS REFUGIADOS (ACNUR). Metodologia e técnicas para entrevistar solicitantes de refúgio: módulo de capacitação. Brasília, DF: Defensoria Pública da União, 2013. Disponível em: https:// www.acnur.org/fileadmin/Documentos/BDL/2014/9666.pdf.

DEUSDARÁ, Bruno; ARANTES, Poliana; ROCHA, Décio. Cruzando fronteiras: a promoção de direitos com refugiados nas práticas de ensino de línguas. Gragoatá: Revista dos Programas de Pós-Graduação do Instituto de Letras da UFF, Niterói, v.22, n. 42, p. 131-153, jan./abr. 2017. Disponível em http://www.gragoata.uff.br/index.php/gragoata/article/ view/909/636. Acesso em: 10 nov. 2018.

GARCIA, Fernanda de Deus. O papel do intérprete comunitário na entrevista de solicitação de refúgio. 2019. 126 f. Dissertação (Mestrado em Estudos da Tradução) - Universidade de Brasília, Brasília, 2019a. Disponível em: https://repositorio.unb.br/ handle/10482/35323. Acesso em: 11 out. 2020.

GARCIA, Fernanda. A interpretação comunitária em entrevistas de solicitação de refúgio: ultrapassando os limites da transferência linguística. Cadernos de Debates Refúgio, Migrações e Direitos Humanos, v. 14, n 14, p. 67 - 82, Brasília: Instituto Migrações e Direitos Humanos. 2019b. Disponível em: https://periodicos.unb.br/index.php/horizontesla/ article/view/886. Acesso em: 05 set. 2020. DOI: https://doi. org/10.26512/rhla.v9i2.886. 
GROSSO, Maria José dos Reis. Língua de acolhimento, língua de integração. Horizontes de Linguística Aplicada, [s. l.], v. 9, n. 2, p. 61-77, 2010.

HALE, Sandra Beatriz. Community Interpreting. New York: Palgrave Macmillan, 2007.

HAMEL, Rainer Enrique. Derechos lingüísticos como derechos humanos: debates y perspectivas. Tradução de Gilvan Muller. Alteridades, México, v. 5, n. 10, p. 11-23, 1995. Disponível em: https://alteridades.izt.uam.mx/index.php/Alte/article/ view/560.

HAMEL, Rainer Enrique. Direitos linguísticos como direitos humanos: debates e perspectivas. In: OLIVEIRA, G. M. de (org.). Declaração Universal dos Direitos Linguísticos: novas perspectivas em política linguística. Campinas: Mercado de Letras; Associação de Leitura do Brasil (ALB); Florianópolis: IPOL, 2003.

INSTITUTO DE PESQUISA ECONÔMICA APLICADA (Ipea). Migrantes, apátridas e refugiados: subsídios para o aperfeiçoamento de acesso a serviços, direitos e políticas públicas no Brasil. Série Pensando o Direito, no 57. Relatório de Pesquisa. Brasília: IPEA, 2015.

LAGARES, Xoán. Qual Política Linguística? Desafios Glotopolíticos Contemporâneos. São Paulo: Parábola Editorial, 2018.

LUSSI, Carmem. Políticas públicas e desigualdades na migração e refúgio. Psicologia USP, [s. l.], v. 26, n. 2, p. 136144, 2015. Disponível em: http://www.scielo.br/pdf/pusp/ v26n2/0103-6564-pusp-26-02-00136.pdf. Acesso em: 05 jul. 2019.

MINISTÉRIO DA JUSTIÇA E SEGURANÇA PÚBLICA (MJSP). Refúgio em números. $4^{a}$ ed. Brasília: Secretaria Nacional de Justiça; Conare, 2019a. Disponível em https://www.justica. gov.br/seus-direitos/refugio/refugio-em-numeros. Acesso em: 28 jul. 2019.

MINISTÉRIO DA JUSTIÇA E SEGURANÇA PÚBLICA (MJSP). Termo de Responsabilidade do Intérprete. Brasília: Secretaria 
Nacional de Justiça; Conare, 2019b. Disponível em: https:// www.justica.gov.br/seus-direitos/refugio/anexos/term. Deresp.Dointerprete_2019_conare1.Pdf. Acesso em: 15 out. 2020.

OLIVEIRA, Gilvan Müller de; SILVA, Julia Izabelle da. Quando barreiras linguísticas geram violação de direitos humanos: que políticas linguísticas o Estado brasileiro tem adotado para garantir o acesso dos imigrantes a serviços públicos básicos? Gragoatá: Revista dos Programas de Pós-Graduação do Instituto de Letras da UFF, Niterói, v.22, n. 42, p. 131-153, jan./ abr, 2017. Disponível em http://www.gragoata.uff.br/index. php/gragoata/article/view/909/636. Acesso em: 10 abr. 2018.

ORGANIZAÇÃO DAS NAÇÕES UNIDAS (ONU). Declaração Universal dos Direitos Humanos. Adotada e proclamada pela Resolução 217 A (III) da Assembleia Geral das Nações Unidas, em 10 de dezembro de 1948.

OZOLINS, Uldis. Factors that determine the provision of Public Service Interpreting: comparative perspectives on government motivation and language service implementation. JoSTrans The Journal of Specialised Translation, [s. l.], issue 14, p 194-215, July, 2010.

PEREIRA, Giselda F. O português como língua de acolhimento e interação: a busca pela autonomia por pessoas em situação de refúgio no Brasil. São Paulo, Cadernos de Pós-Graduação em Letras, São Paulo, v. 17, n. 1, 15 ago. 2017. Disponível em: http://editorarevistas.mackenzie.br/index.php/cpgl/article/ view/10248.

SCHNEIDER-MIZONY, Odile. Les droits linguistiques sont-ils solubles dans l'espace?, Les Cahiers du GEPE, Migration(s) et langues; langues et espace(s), Strasbourg: Presses universitaires de Strasbourg, n. 9, 2018. Disponível em: http://www. cahiersdugepe.fr/index.php?id=3163.

SILVA, Julia Izabele da. O debate sobre direitos linguísticos e o lugar do linguista na luta dos sujeitos falantes de línguas minorizadas: quem são os protagonistas? RBLA, Belo Horizonte, v. 17, n. 4, p. 663-690, 2017. Disponível em http:// 
www.scielo.br/pdf/rbla/v17n4/1984-6398-rbla-201711347.pdf. Acesso em: 19 dez. 2018.

VARENNES, Fernand de. Language Rights as an Integral Part of Human Rights. IJMS: International Journal on Multicultural Societies, v. 3, n. 1, p. 15-25, 2001, Unesco. Disponível em <http:// www.unesco.org/shs/ijms/vol3/issue1/art2>. Acesso em: 13 mar. 2019.

VARENNES, Fernand de. The human rights dimension and challenges of linguistic rights. In: International conference

\section{Abstract \\ Linguistic Rights of Refugee Applicants in Brazil: The Presence of the Linguistic Mediator in the Refuge Request as a Guarantee of Human Rights}

In this study, which is established in the context of studies in Linguistic Policies, we concentrate on the centrality of the role of the community interpreter as a guarantee to ensure linguistic rights in the contemporary Brazilian migratory context. Our focus is particularly on the determinant situation of the asylum seeker's interview with the eligibility officer of the National Refugee Committee - Conare, a peculiar sociolinguistic situation that underlies the decision on granting refugee status in the country. We emphasize the absence of an explicit current policy, especially in terms of linguistic rights, an institutional vacuum that is felt even more considering the impacts of forced displacement, in the midst of a global humanitarian crisis resulting in a significant increase in mobility as a consequence of asylum applications in Brazil and in the world. The investigation consisted of a qualitative descriptive research of the actions performed by the State and Civil Society institutions, based on legislation and on official websites concerning refuge in Brazil. To address the challenges of the analysis, a theoretical framework of Language 
Policies and Glotopolytics is used (CALVET, 2007; LAGARES, 2018), with focus on linguistic rights studies (HAMEL, 1995, 2003; OLIVEIRA; SILVA, 2017; SCHNEIDERMIZONY, 2018; VARENNES, 2001, 2015). Based on this corpus, there is an urgent need to implement actions, especially linguistic mediation in institutional contexts, initiatives that should be guided by the Brazilian State, whose inertia has been counterbalanced by the academia and Civil Society.

Keywords: Language Policies. Refuge. Linguistic Rights. Community Interpreting.

Ana Cristina Balestro é doutoranda em Estudos da Linguagem pela Universidade Federal Fluminense (UFF) e integrante do banco de intérpretes voluntários do grupo de pesquisa e extensão Mobilang (UnB). Durante seu mestrado, também pela UFF, pesquisou sobre Políticas Linguísticas no contexto de refúgio no Rio de Janeiro. Possui especialização em Políticas Públicas para a Igualdade na América Latina, pelo Conselho Latino-Americano de Ciências Sociais (CLACSO) e graduação em Letras pela Universidade Federal do Rio Grande do Sul (UFRGS).

Sabine Gorovitz é professora associada do Departamento de Línguas Estrangeiras e Tradução, do Instituto de Letras da Universidade de Brasília - UnB desde 1996. É responsável pelo eixo de pesquisa "Contato de línguas e Direitos e Políticas linguísticas" do Programa de Pósgraduação em Estudos da Tradução Postrad - do mesmo Departamento, com pesquisas sobre contatos linguísticos em contextos migratórios; políticas e direitos linguísticos; tradução, migração, interpretação comunitária e mediação linguística e intercultural. 